\title{
Starch Based Bio-Plastics: The Future of Sustainable Packaging
}

\author{
Ravindra V. Gadhave, Abhijit Das, Prakash A. Mahanwar, Pradeep T. Gadekar \\ Department Polymer and Surface Engineering, Institute of Chemical Technology, Mumbai, India \\ Email: Ravi.gadhave3@gmail.com
}

How to cite this paper: Gadhave, R.V., Das, A., Mahanwar, P.A. and Gadekar, P.T. (2018) Starch Based Bio-Plastics: The Future of Sustainable Packaging. Open Journal of Polymer Chemistry, 8, 21-33. https://doi.org/10.4236/ojpchem.2018.82003

Received: March 10, 2018

Accepted: May 27, 2018

Published: May 30, 2018

Copyright (c) 2018 by authors and Scientific Research Publishing Inc. This work is licensed under the Creative Commons Attribution International License (CC BY 4.0).

http://creativecommons.org/licenses/by/4.0/

(c) (i) Open Access

\begin{abstract}
Petroleum derived plastics dominate the food packaging industry even today. These materials have brought a lot of convenience and attraction to agro, food and packaging industry. These materials also have brought along with them problems relating to the safe-disposal and renewability of these materials. Due to the growing concern over environmental problems of these materials, interest has shifted towards the development and promoting the use of "bio-plastics". Bio-plastic is a term used for sustainable packaging materials derived from renewable resources i.e. produced from agro/food sources, materials such as starch, cellulose, etc. and which are considered safe to be used in food applications. To enhance the mechanical properties, and water barrier properties, it can be blended easily with other polymer as well as nano fillers. The current paper is a review of the progress of research in starch based sustainable packaging materials.
\end{abstract}

\section{Keywords}

Bioplastic, Starch, Packaging, Sustainable

\section{Introduction}

Reason for transition from synthetic plastic materials to biobased plastic materials

Synthetic polymers or petrochemical-based plastics like polyamides (PA), nylon, polystyrene (PS), Teflon, polyethylene terephthalate (PET), polyethylene (PE) etc. have been widely used for food packaging applications due to their excellent thermal and rheological properties, lightweight, easy to manipulate, and install in a diverse range of applications, gas and water barrier properties, esthetic qualities, and cost [1]. The oil that is used as a raw material, as well as the oil required for energy, consumes between six to eight percent of the total world 
oil production. Although this is a small percentage, the amount of petroleum used to make plastic does contribute to the depletion of fossil fuels. The rate of consumption influences the overall price of petroleum, contributing to the current rise in raw material costs. Plastics derived from petroleum are made from synthetic polymers [2]. Their utility includes but is definitely not limited to agriculture, aerospace, automobile, construction, sports, domestic, and households. Increase in population and industrial growth have resulted in the increased production of synthetic polymers and allied materials [3]. Polyethylene more often used as carry bag and more is produced annually [4]. Non recyclable and synthetic polymeric materials are causing a serious concern in environmental related issues. In particular, the plastic bags which are discarded into the environment have become a menace [5]. Significant quantities of plastic have gathered in the natural environment and in landfills. Wasted plastic also contaminates a wide range of natural terrestrial, freshwater and marine habitats. There are accounts of inadvertent contamination of soils with small polymer fragments as a consequence of spreading sewage sludge [6], of fragments of plastic and glass contaminating compost prepared from municipal solid waste [7] and of plastic being carried into streams, rivers and ultimately the sea with rain water and flood events [8]. Most polymers are buoyant in water, and since items of plastic debris such as cartons and bottles often trap air, substantial quantities of plastic debris accumulate on the sea surface and may also be washed ashore. As a consequence, plastics represent a considerable proportion $(50 \%-80 \%)$ of shoreline debris [9].

Phthalates based plasticizers and BPA can bio-accumulate in organisms, but there is much variability between species and individuals according to the type of plasticizer and experimental purpose. However, concentration factors are generally higher for invertebrates than vertebrates, and can be especially high in some species of molluscs and crustaceans. Plastics contain phthalates, BPA, flame retardants, cadmium, lead and organo tins, all of which have been shown in animal studies to result in obesity [10]. In addition, the monomer used to manufacture PVC plastic, vinyl chloride, is a known carcinogen and exposure can cause angiosarcoma of the liver among factory workers [11] [12].

In recent decades, the plastic industry and the academic community have been together looking for new raw materials to replace the petrochemical polymers, which are produced from nonrenewable resources [13].

Biodegradable plastic made from renewable resources is decreases dependence on petroleum and reduces the amount of waste material, while still yielding a product that provides similar benefits of traditional plastics [14]. The major difference between synthetic polymers and natural polymers is that the presence of oxygen and nitrogen in the natural polymers. The oxygen and nitrogen in the polymer structure permit the polymer to biodegrade [15]. Bio-based polymers have been shown to be a viable alternative to replace these fossil sources while also having environmental advantages, such as decreasing toxic emissions [16]. 
Most traditional plastics are inert to microbial attack, and the development of biodegradable packaging, these derived from renewable natural resources, has gained increasing interest [17]. Target markets for biodegradable polymers include packaging materials like trash bags, loose-fill foam, food containers, film wrapping, laminated paper, hygiene products like diaper back sheets and cotton swabs, consumer goods like fast-food tableware and containers, egg cartons, and toys, and agricultural tools like mulch films and planters etc. [18].

Cellulose, lignin, and starch are commonly available in nature. Cellulose is abundant in all plants, although some plants produce more than others. Lignin is typically found in wood, and starch is common in plants such as corn, potatoes, and wheat. Plants, wood, corn, potatoes, and wheat are all raw materials that are renewable, biodegradable and easily available [19]. Packaging materials with biodegradable plastic is more expensive than traditional petroleum based plastic. Packaging materials based on these natural materials may be a solution to help control the environmental pollution and resolve other problems posed by non-degradable synthetic polymers [20].

\section{Biodegradability and Compostability}

Bio-based is defined in European standard EN 16575 as "derived from biomass". Biodegradable materials are materials that can be broken down by microorganisms like bacteria or fungi into water, naturally occurring gases like carbon dioxide $\left(\mathrm{CO}_{2}\right)$ and methane $\left(\mathrm{CH}_{4}\right)$ and biomass. Biodegradability depends strongly on the environmental conditions: temperature, presence of microorganisms, and availability of oxygen and water [21] [22].

Compostable materials are materials that break down at composting conditions. Industrial composting conditions require elevated temperature $\left(55^{\circ} \mathrm{C}\right.$ $60^{\circ} \mathrm{C}$ ) combined with a high relative humidity and the presence of oxygen, and they are in fact the most optimal when compared against other degradation conditions like in soil, surface water and marine water. Compliance with EN 13432 is considered a good measure for industrial compostability of packaging materials. According to the EN13432 standard, plastic packaging can only be called compostable [23].

\section{Bioplastic as Packaging Material}

Polylactic acid (PLA): Polylactic acid (PLA) is a 100\% bio-based plastic that is currently being used in packaging applications. PLA is very suitable for the manufacture of compostable packaging products. Specific benefits of PLA in packaging applications are its transparency, gloss, stiffness, printability, process ability and excellent aroma barrier. PLA is approved for direct contact with food and is applied in a range of packaging products. PLA is frequently used in combination with other bio-based and biodegradable polymers to improve stiffness and strength and to reduce costs.

Cellophane: Cellophane films are highly transparent, and stiff. Cellophane 
films can be colored and are well known as candy wrappings. The biodegradable films are available in a wide range of grades, and they can be used to pack products ranging from cheese to coffee and chocolate.

Cellulose acetate: When extensively modified, cellulose can become thermoplastic. An example is cellulose acetate. This material is rather expensive and rarely used in packaging applications. The most frequently used biodegradable polyesters are polybutylene adipate terephthalate (PBAT), Polycaprolactone (PCL) and Polybutylene succinate (PBS).

Starch: Starch based flexible films containing polyesters to improve processability, water resistance and tear strength [24].

\section{Why Use Starch as Packaging Material?}

Starch is used as a starting material for a wide range of green materials. $75 \%$ of all organic material on earth is present in the form of polysaccharides. An important polysaccharide is starch. Plants synthesize and store starch in their structure as an energy reserve. Starch is found in seeds and in tubers or roots of the plants. Most of the starch produced worldwide is derived from corn [25].

Starch is generally extracted from plant resource by wet milling processes. Starch consists of two types of anhydroglucose polymers amylose and amylopectin. Amylose is essentially a linear polymer in which anhydroglucose units are predominantly connected through $\alpha$-D-(1, 4) glucosidic bonds. Amylopectin is a branched polymer, containing periodic branches linked with the backbones through $\alpha$-D-(l, 6) glucosidic bonds. The content of amylose and amylopectine in starch varies and largely depends on the starch source [26]-[36]. Starch is found abundantly in corn, wheat, rice, potato, tapioca, pea, and many other botanical resources [37].

\section{Starch: The Future of Sustainable Packaging}

\section{1) Starch blends with compostable polymers.}

Starch based plastics are complex blends of starch with compostable plastics such as PLA, PBAT, PBS, PCL and PHAs. Blending of starch with plastics improves water resistance, processing properties and mechanical properties. Starch based trays are not transparent. Other packaging products Starch based materials are frequently used in loose fill foams for transport packaging. Another application is in service ware like cups, plates and cutlery. Biodegradable films, with starch as a matrix, were developed and reinforced with wheat and corn hulls. It was observed that the addition of hulls enhanced the modulus, tensile strength, and impact strength of the starch matrix at the expense of its elongation. The water-vapor transmission rate results show that corn starch was more efficient in reducing the water-vapor permeability than wheat hulls [38].

The challenges for researchers and the packaging industry in terms of producing starch-based blends with commercial utility are:

a) Overcoming miscibility problems at high starch contents, 
b) Avoiding mechanical property deterioration at high starch contents, even in compatibilized blends,

c) Reducing costs, especially for biodegradable starch-polyester blends at low starch contents (<30 wt.\%) [39].

2) Antimicrobial packaging film:

Antimicrobial packaging refers to the integration of an antimicrobial agent into packaging systems for the purpose of preventing microbial growth on food products and extending its shelf life [40] [41] [42].

The packaging materials may acquire antimicrobial activity

i) By incorporating antimicrobial components in a polymer matrix,

ii) Surface irradiation of polymer matrix which produces reactive oxidizing species,

iii) By gas emission/flush through modified atmosphere packaging [43],

iv) By using inherently antimicrobial polymer resins.

The use of antimicrobials in food packaging systems has been motivated with the increasingly global food-borne outbreaks with relation to health and safety concerns [44] [45].

Antimicrobial packaging has two main categories, namely migratory and non-migratory packaging systems.

- Migratory packaging system allows the reversible release of non-volatile or volatile active components from polymer matrix to food constituents or packages headspace by diffusion and/or partition at interfaces.

- In the non-migratory system, the active component is irreversibly tethered to the package's surface and no diffusivity of the antimicrobial agents occur [46] [47].

These additives can be deactivated in the food matrix or migrate out of the food surface towards locations in the food where initial microbial attacks are not taking place [48] [49]. The natural antimicrobial agents have broad spectrum actions against most of pathogenic and food spoilage microorganisms. Additionally, nanomaterials from titanium [50], magnesium, copper, silver [51] [52], platinum, gold and zinc have also received attention in antimicrobial food packaging due to their large surface-volume ratio [53]. Ternary blend films were prepared with different ratios of starch-polyvinyl alcohol with citric acid to obtain films with better antibacterial, mechanical, and thermal properties [54]. In other work two essential oils, Zataria multiflora Boiss (ZEO) or Mentha pulegium (MEO) at three levels $(1 \%, 2 \%$ and $3 \%(\mathrm{v} / \mathrm{v}))$, were incorporated into starch films using a solution casting method to improve the mechanical and water vapour permeability (WVP) properties and to impart antimicrobial activity. Plants contain polyphenolic compounds and a large number of them were used as antioxidant, antibacterial and antifungal properties [55] [56] [57].

3) Starch based nanocomposite films.

Natural materials such as clay nanofillers with starch use to develop biodegradable nanocomposite packaging films to address issues of environmental im- 
pact, agriculture sustainability [58]. 7 - 9 parts of nano-Montmorillonite in a plastic film has shown high strength, and prepared film is also capable of achieving complete degradation, environment-friendly after being discarded, capable of being prepared into plastic bags, preservative films and the like for food packages, and worthy of large-area popularization [59]. In some case addition of light calcium carbonate and rock powder, not only the qualities of the finished products were improved, but also the cost was reduced by $45 \%$ while ensuring a good degradation effect [60]. Addition of nanosilica improved the mechanical properties of the nanocomposite sheets. Tensile strength increased, adversely affecting the elongation at break. The sheets also displayed improved water resistance while those without nanosilica disintegrated within two hours of immersion in distilled water at $25^{\circ} \mathrm{C}$. Food packaging was originally used to protect food against heat, light, moisture, oxygen, microbial attack, insects and other impurities [61]. In one study, a corn starch-based nanocomposite sheet was prepared using nanosilica/from rice hull ash to enhance mechanical and water absorption packaging properties of corn starch [62]. Cellulose nanofillers could be considered as environmental friendly and renewable nanofillers. Nanocrystalline cellulose (NCC) from sugar palm fibers and nanocrystals from sugar palm starch were prospective nano-reinforcement or nano-filler to enhance the properties of sugar palm starch-based films as high-performance packaging material [63]. Nano-clays have been added to various polymeric matrices in very small quantities to improve film properties.

Nano-fillers had also been introduced to induce higher mechanical strength and improve barrier against gases and water vapor. These fillers are capable of improving barrier and mechanical properties by decreasing filler dimensions and also reducing production cost due to lower material consumption. Moreover, Nano-filler reinforcement affects polymer crystallinity, reduces transport and enhanced water absorption. The addition of nanoclay to starch composite films has been found to improve the mechanical strength and transport properties. Micro porous, aluminosilicate minerals like Zeolites can also use as fillers in starch-based films. Studies show that Zeolites leads to the enhancement of Young's modulus and reduction of gas and vapor transport and also water solubility.

Nano-cellulose is also added to starch in order to enhance starch film properties. Based on the results, nano-cellulose leads to the improvement of mechanical properties up to $70 \%$. NCC was used as a nano-scale additive into the starch chitosan and gelatin-chitosan nano-composite films. Chitosan was used to enhance antibacterial and anti-fungal properties. Many investigations were developed on the natural fibers potential as reinforcements for composites [64] [65] [66]. Starch and poly (vinyl alcohol) (PVOH)-based packaging is of great importance and had additional benefits over petroleum-based packaging due to abundant availability, biodegradability and compatibility. Presence of laponite $\mathrm{RD}$ improved the mechanical barrier properties of starch/PVOH matrix up to 
$10 \%$ level of laponite $\mathrm{RD}$ because of better surface interface interaction between polymer matrix and layers of laponite RD [67].

Film-forming formulations comprising starch, ethylene acrylic acid copolymer, and optionally polyethylene, can be blown into films upon neutralization of a portion of the copolymer acid functionality. The resultant biodegradable films had potential application as agricultural mulch, garbage bags, and various types of packaging [68] [69]. The elaboration of flexible films from cassava starch for the manufacture of biodegradable packaging useful in the packing and packaging of dry foods and other products. The novel films were produced by extrusion of a mixture of cassava starch and plasticizer [70]. A series of corn starch films with varying concentrations $(0 \%-20 \%$, W/W) of citric acid (CA) and Carboxymethyl cellulose (CMC) were produced by casting method. As a result of its multi-carboxylic structure, interaction could take place between the carboxyl groups of CA and the hydroxyl groups on the starch. Such an interaction would improve the water resistibility due to reducing available $\mathrm{OH}$ groups of starch. Cellulose-based fibers are widely used as biodegradable filler. When natural fibers were mixed with starch, the mechanical properties of the resulted composite were obviously improved, because the chemical similarities of starch and plant fibers provide a good interaction. There are few papers about the $\mathrm{CMC} / \mathrm{starch}$ biocomposite properties. The addition of CMC improved the moisture resistance of the composites [71].

\section{4) Heat sealing packaging.}

Heat sealing capacity of native and acetylated corn starch based films was evaluated to develop biodegradable packages, such as bags. Acetylated starch addition reinforced $80 \%$ sealing resistance of starch films. Numerous sealing techniques are available. On the other hand, the glass transition temperature $\left(T_{\mathrm{g}}\right)$ is an important parameter that determines both the mechanical and barrier properties of amorphous polymers and controls the crystallization kinetics of these materials. Acetylated starch addition in film formulation reinforced the sealing resistance. Heat sealing tests showed that un-plasticized films exhibited adhesive failures while those containing glycerol presented a rupture near the zip [72]. Rice flour is a starchy material with low-cost, because it can be produced from rice that is broken during processing. Films from rice starch and rice flour were prepared by casting, with glycerol or sorbitol as plasticizer. Rice flour films prepared had similar mechanical properties to those of starch based films. However, their water vapor permeabilities were two times higher than those of starch based films. The production of biodegradable and edible films from carbohydrates and proteins adds value to low-cost raw materials and can play an important role in food preservation [73].

It has been found that with increase in glycerol content in the Potato Starch films increased the macromolecular mobility, and the potato starch films became less stiff and more flexible. The transparency was found to decrease [74]. Active and smart biodegradable films from cassava starch and glycerol with $5 \mathrm{wt} \%$ of 
different natural extracts such as green tea and basil were prepared and tested for degradation [75]. These films degraded in soil under two weeks and were thermally stable up to $240^{\circ} \mathrm{C}$. The incorporation of extracts of green tea and basil was found to make films with lower water vapor permeability retaining their flexibility.

5) Starch grafted emulsions for packaging.

Grafting was an important technique for modifying the physical and chemical properties of polymers. The graft copolymerization of synthetic polymers onto a starch backbone was one of the best ways of improving the properties of starch. Starch grafted on vinyl emulsion also undergoes biodegradation and can be used as sustainable packaging material [76].

\section{Conclusion}

The implementation of sustainable practices will help minimize our impact on the environment and conserve resources for future generations. Industrial progress in packaging technology in future appears to be moving forwards newer breed of bio-materials. To that end, there is a need to perpetuate the culture of environmental stewardship and sustainability that has grown stronger in recent years. Although some of the starch-based materials and other biopolymers may not currently be cost-competitive with petroleum plastics, this may change as petroleum prices continue to increase. Improved the properties of starch-based plastics by blending starch with other polymers, using starch in composite materials, and using starch as a biodegradable feedstock to make other biopolymers have been successful in developing viable replacements for petroleum based plastics. The prospects for starch in the packaging sector continue to become brighter as the market for sustainable plastics drives further innovation and development.

\section{Futuristic Approach}

Focused research is needed in bringing more values such as making the packaging material simpler yet smarter, where consumer is able to assess the quality, safety, shelf-life, and nutritional values of the contents of packet with cost effectiveness. The benefits however should not come at the cost of the cost of curing environmental issues and should eco-friendly.

\section{References}

[1] Sharma, C., Manepalli, P.H., Thatte, A., Thomas, S., Kalarikkal, N. and Alavi, S. (2017) Biodegradable Starch/PVOH/Laponite RD-Based Bionanocomposite Films Coated with Graphene Oxide: Preparation and Performance Characterization for Food Packaging Applications. Colloid and Polymer Science, 295, 1695-1708. https://doi.org/10.1007/s00396-017-4114-9

[2] Averous, L., Fringant, C. and Moro, L. (2001) Starch-Based Biodegradable Materials Suitable for Thermodynamics Packaging. Starch/Starke, 53, 368-371. https://doi.org/10.1002/1521-379X(200108)53:8<368::AID-STAR368>3.0.CO;2-W 
[3] Carraher, C.E.Jr. and Sperling, L.H. (eds.) (1983) Polymer Applications of Renewable-Resource Materials. Plenum Press, New York.

[4] Ching, C., Kaplan, D. and Thomas, E. (eds.) (1993) Biodegradable Polymers and Packaging. Technomic Publishing Company, Inc., Lancaster.

[5] Tharanathan, R.N. (2003) Biodegradable Films and Composite Coatings: Past, Present, and Future. Trends in Food Science and Technology, 14, 71-78. https://doi.org/10.1016/S0924-2244(02)00280-7

[6] Zubris, K.A.V. and Richards, B.K. (2005) Synthetic Fibers as an Indicator of Land Application of Sludge. Environmental Pollution, 138, 201-211.

https://doi.org/10.1016/j.envpol.2005.04.013

[7] Brinton, W.F. (2005) Characterization of Man-Made Foreign Matter and Its Presence in Multiple Size Fractions from Mixed Waste Composting. Compost Science \& Utilization, 13, 274-280. https://doi.org/10.1080/1065657X.2005.10702251

[8] Thompson, R., Moore, C., Andrady, A., Gregory, M., Takada, H. and Weisberg, S. (2005) New Directions in Plastic Debris. Science, 310, 1117.

https://doi.org/10.1126/science.310.5751.1117b

[9] Barnes, D.K.A., Galgani, F., Thompson, R.C. and Barlaz, M. (2009) Accumulation and Fragmentation of Plastic Debris in Global Environments. Philosophical Transactions of the Royal Society B, 364, 1985-1998.

https://doi.org/10.1098/rstb.2008.0205

[10] Heindel, J.J. and vom Saal, F.S. (2009) Overview of Obesity and the Role of Developmental Nutrition and Environmental Chemical Exposures. Molecular and Cellular Endocrinology, 304, 90-96.

[11] Bolt, H.M. (2005) Vinyl Chloride-A Classical Industrial Toxicant of New Interest. Critical Reviews in Toxicology, 35, 307-323. https://doi.org/10.1080/10408440490915975

[12] Gennaro, V., Ceppi, M., Crosignani, P. and Montanaro, F. (2008) Reanalysis of Updated Mortality among Vinyl and Polyvinyl Chloride Workers: Confirmation of Historical Evidence and New Findings. BMC Public Health, 8, 21. https://doi.org/10.1186/1471-2458-8-21

[13] Avella, M., de Vlieger, J.J., Errico, M.E., Fischer, S., Vacca, P. and Vope, M.G. (2009) Biodegradable Starch/Clay Nanocomposite Films for Food Packaging Applications. Food Chemistry, 93, 548-558.

[14] Stevens, E.S. (2002) Green Plastics: An Introduction to the New Science of Biodegradable Plastics. Princeton University Press, Princeton.

[15] Biliaderis, C.G. (1998) Structures and Phase Transitions of Starch Polymers, in Polysaccharide Association Structures in Food. Marcel Dekker, Walter RH, New York, 57-168.

[16] Imre, B. and Pukánszky, B. (2013) Compatibilization in Bio-Based and Biodegradable Polymer Blends. European Polymer Journal, 49, 1215-1233. https://doi.org/10.1016/j.eurpolymj.2013.01.019

[17] Nafchi, A.M., Moradpour, M., Saeidi, M. and Alias, A.K. (2013) Thermoplastic Starches: Properties, Challenges, and Prospects. Starch Starke, 65, 61-72. https://doi.org/10.1002/star.201200201

[18] Erkske, D., Viskere, I., Dzene, A., Tupureina, V. and Savenkova, L. (2006) Bio-Based Polymer Composite for Films and Coatings. Proceedings of the Estonian Academy of Sciences. Chemistry, 55, 70-77.

[19] Scott, G. (2002) Degradable Polymers Principles and Applications. 2nd Edition, 
Kluwer Academic Publishers, Boston. https://doi.org/10.1007/978-94-017-1217-0

[20] Butschli, J. (2005) Packagers Embrace Renewable Resources. Packaging World Magazine.

[21] Van der Zee, M. (1997) Structure-Biodegradability Relationships of Polymeric Materials. Doctoral Thesis, Universiteit Twente, Enschede.

[22] Wu, H.J. and Dunn, S.C. (1995) Environmentally Responsible Logistics Systems. International Journal of Physical Distribution and Logistics Management, 25, 20-38. https://doi.org/10.1108/09600039510083925

[23] Bos (2016) Bioplastics and Food-Enemies or Allies. Sustainable Plastics 2016 Conference, Köln, 1-2 March 2016.

[24] Marvizadeh, M.M., Oladzadabbasabadi, N., Mohammadi Nafchi, A. and Jokar, M. (2017) Preparation and Characterization of Bionanocomposite Film Based on Tapioca Starch/Bovine Gelatin/Nanorod Zinc Oxide. International Journal of Biological Macromolecules, 99, 107. https://doi.org/10.1016/j.ijbiomac.2017.02.067

[25] Asaf Kleopas, S. (2008) Synthesis and Properties of Starch Based Bio-Materials. University of Groningen, Groningen.

[26] Wool, R.P. and Sun, X. (2005) Bio-Based Polymer and Composites. Elsevier Academic Press, Cambridge.

[27] Huda, M.S., Mohanty, A., Drzal, L.T., Schut, E. and Misra, M. (2005) Green Composites from Recycled Cellulose and Poly (Lactic Acid): Physico-Mechanical and Morphological Properties Evaluation. Materials Science, 40, 4221-4229.

[28] Graupner, N. (2008) Application of Lignin as Natural Adhesion Promoter in Cotton Fiber-Reinforced Poly(Lactic Acid) (PLA) Composites. Materials Science, 43, 5222-5229. https://doi.org/10.1007/s10853-008-2762-3

[29] Avella, M., Bogoeva-Gaceva, G., Buzarovska, A., Errico, M.E., Gentile, G. and Grozdanov, A. (2008) Poly(Lactic Acid)-Based Biocomposites Reinforced with Kenaf Fibers. Journal of Applied Polymer Science, 108, 3542-3551. https://doi.org/10.1002/app.28004

[30] Hu, R. and Lim, J. (2007) Fabrication and Mechanical Properties of Completely Biodegradable Hemp Reinforced PLA Composites. Journal of Composite Materials, 41, 1655-1669. https://doi.org/10.1177/0021998306069878

[31] Tokoro, R., Vu, D.M., Okubo, K., Tanaka, T., Fujii, T. and Fujiura, T. (2008) How to Improve Mechanical Properties of PolyLactic Acid with Bamboo Fibers. Materials Science, 43, 775-787. https://doi.org/10.1007/s10853-007-1994-y

[32] Shikamoto, N., Ohtani, A., Leong, Y.W. and Nakai, A. (2007) Fabrication and Mechanical Properties of Jute/PLA Composites. In: 22nd Technical Conference of the American Society for Composites 2007, Composites, Enabling a New Era in Civil Aviation, Curran Associates, Inc., Red Hook, 151.

[33] Huda, M.S., Drzal, L.T., Mohanty, A.K. and Misra, M. (2008) Effect of Chemical Modifications of the Pineapple Leaf Fiber Surfaces on the Interfacial and Mechanical Properties of Laminated Biocomposite. Composite Interfaces, 15, 169-191. https://doi.org/10.1163/156855408783810920

[34] Zhao, Y.Q., Lau, K.T., Liu, T., Cheng, S., Lam, P.M. and Li, H.L. (2008) Production of a Green Composite, Mixture of Poly(Lactic Acid) and Keratin Fibers from Chicken Feathers. Advanced Materials Research, 47-50, 1225-1228.

[35] Wang, K.H., Wu, T.M., Shih, Y.F. and Huang, C.M. (2008) Water Bamboo Husk Reinforced Poly (Lactic Acid) Green Composites. Polymer Engineering \& Science, 48, 1833-1839. https://doi.org/10.1002/pen.21151 
[36] Niranjana Prabhu, T. and Prashantha, K. (2016) A Review on Present Status and Future Challenges of Starch Based Polymer Films and Their Composites in Food Packaging Applications, Polymer Composites. https://doi.org/10.1002/pc.24236

[37] Ali, A., Yu, L., Liu, H., Khalid, S., Meng, L. and Chen, L. (2017) Preparation and Characterization of Starch-Based Composite Films Reinforced by Corn and Wheat Hulls. Journal of Applied Polymer Science, 134. https://doi.org/10.1002/app.45159

[38] Masoomi, M., Tavangar, M. and Razavi, S.M.R. (2015) Preparation and Investigation of Mechanical and Antibacterial Properties of Poly(Ethylene Terephthalate)/Chitosan Blend. RSC Advances, 5, 79200-79206. https://doi.org/10.1039/C5RA06372H

[39] Ochoa, T.A., Almendarez, B.E.G., Reyes, A.A., Pastrana, D.M.R., Lopez, G.F.G., Belloso, O.M., et al. (2016) Design and Characterization of Corn Starch Edible Films Including Beeswax and Natural Antimicrobials. Food and Bioprocess Technology, 10, 103-114. https://doi.org/10.1007/s11947-016-1800-4

[40] Sung, S.-Y., et al. (2013) Antimicrobial Agents for Food Packaging Applications. Trends in Food Science \& Technology, 33, 110-123. https://doi.org/10.1016/j.tifs.2013.08.001

[41] Liu, H., Du, Y.M., Wang, X.H. and Sun, L. (2004) Chitosan Kills Bacteria through Cell Membrane Damage. International Journal of Food Microbiology, 95, 147-155. https://doi.org/10.1016/j.ijfoodmicro.2004.01.022

[42] Lavoine, N., Desloges, I. and Bras, J. (2014) Microfibrillated Cellulose Coatings as New Release Systems for Active Packaging. Carbohydrate Polymers, 103, 528-537. https://doi.org/10.1016/j.carbpol.2013.12.035

[43] Fortunati, E., Luzi, F., Puglia, D., et al (2013) Ternary PVA Nanocomposites Containing Cellulose Nanocrystals from Different Sources and Silver Particles: Part II. Carbohydrate Polymers, 97, 837-848. https://doi.org/10.1016/j.carbpol.2013.05.015

[44] Ehivet, F.E., Min, B., Park, M.K. and Oh, J.H. (2011) Characterization and Antimicrobial Activity of Sweetpotato Starch-Based Edible Film Containing Origanum (Thymus capitatus) Oil. Journal of Food Science, 76, C178-C184. https://doi.org/10.1111/j.1750-3841.2010.01961.x

[45] Vartiainen, J., Motion, R., Kulonen, H., Rättö, M., Skyttä, E. and Ahvenainen, R. (2004) Chitosan-Coated Paper: Effects of Nisin and Different Acids on the Antimicrobial Activity. Journal of Applied Polymer Science, 94, 986-993. https://doi.org/10.1002/app.20701

[46] Azlin-Hasim, S., Cruz-Romero, M.C., Ghoshal, T., Morris, M.A., Cummins, E. and Kerry, J. (2015) Application of Silver Nanodots for Potential Use in Antimicrobial Packaging Applications. Innovative Food Science \& Emerging Technologies, 27, 136-143. https://doi.org/10.1016/j.ifset.2014.10.012

[47] Kugel, A., Stafslien, S. and Chisholm, B.J. (2011) Antimicrobial Coatings Produced by "Tethering" Biocides to the Coating Matrix: A Comprehensive Review. Progress in Organic Coatings, 72, 222-252. https://doi.org/10.1016/j.porgcoat.2011.07.004

[48] Rodríguez, A., Batlle, R. and Nerín, C. (2007) The Use of Natural Essential Oils as Antimicrobial Solutions in Paper Packaging. Part II. Progress in Organic Coatings, 60, 33-38. https://doi.org/10.1016/j.porgcoat.2007.06.006

[49] Takala, N., Vu, K.D., Salmieri, S., Khan, R.A. and Lacroix, M. (2013) Antibacterial Effect of Biodegradable Active Packaging on the Growth of Escherichia coli, Salmonella typhimurium and Listeria monocytogenes in Fresh Broccoli Stored at $4{ }^{\circ} \mathrm{C}$. Food Science and Technology, 53, 499-506. https://doi.org/10.1016/j.lwt.2013.02.024 
[50] El-Wakil, N.A., Hassan, E.A., Abou-Zeid, R.E. and Dufresne, A. (2015) Development of Wheat Gluten/Nanocellulose/Titanium Dioxide Nanocomposites for Active Food Packaging. Carbohydrate Polymers, 124, 337-346. https://doi.org/10.1016/j.carbpol.2015.01.076

[51] Reddy, N. and Yang, Y.Q. (2010) Citric Acid Cross-Linking of Starch Films. Food Chemistry, 118, 702-711. https://doi.org/10.1016/j.foodchem.2009.05.050

[52] Mlalila, N.G., Swai, H.S., Hilonga, A. and Kadam, D.M. (2016) Antimicrobial Dependence of Silver Nanoparticles on Surface Plasmon Resonance Bands against Escherichia coli. Nanotechnology, Science and Applications, 10, 1-9. https://doi.org/10.2147/NSA.S123681

[53] Ghasemlou, M., Aliheidari, N., Fahmi, R., Shojaee-Aliabadi, S., Keshavarz, B., Cran, M.J. and Khaksar, R. (2013) Physical, Mechanical and Barrier Properties of Corn Starch Films Incorporated with Plant Essential Oils. Carbohydrate Polymers, 98, 1117-1126. https://doi.org/10.1016/j.carbpol.2013.07.026

[54] Wu, Z., Wu, J., Peng, T., Li, Y., Lin, D., Xing, B., Li, C., Yang, Y., Yang, L., Zhang, L. and Ma, R. (2017) Preparation and Application of Starch/Polyvinyl Alcohol/Citric Acid Ternary Blend Antimicrobial Functional Food Packaging Films. Polymers, 9, 102. https://doi.org/10.3390/polym9030102

[55] Hung, M., Yu, J. and Ma, X. (2006) High Mechanical Performance MMT-Urea and Formamide Plasticized Thermoplastic Cornstarch Biodegradable Nanocomposite. Carbohydrate Polymers, 63, 393-399. https://doi.org/10.1016/j.carbpol.2005.09.006

[56] Glenn, G.M., Orts, W., Imam, S., Chiou, B.-S. and Wood, D.F. (2014) Starch Plastic Packaging and Agriculture Applications. Publications from USDA-ARS/UNL Faculty, Paper 1459. http://www.digitalcommons.unl.edu/usdaarsfacpub/1459

[57] Chen, L. (2017) Preparation Method of Potato Starch-Based Degradable Plastic Film. CN 104292479 A, 11 January 2017.

[58] Issa, A., Ibrahim, S.A. and Tahergorabi, R. (2016) Sweet Potato Starch/Clay Nanocomposite Film: New Material for Emerging Biodegradable Food Packaging. MOJ Food Processing \& Technology, 3, Article ID: 00073.

[59] Wan, H. and Chen, K. (2015) Ramie Stick Reinforced Starch-Based Fully-Degradable Plastic Film and Preparation Method Thereof. CN 104893004 A, 09 Sept. 2015.

[60] Sun, Y. (2015) Degradable Starch-Based Plastic Masterbatch and Preparation Method Thereof. EP 2586821 A1, 12 Feb. 2015.

[61] Tang, S., Zou, Xiong, H. and Tang, H. (2008) Effect of Nano-SiO2 on the Performance of Starch/Polyvinyl Alcohol Blends. Carbohydrate Polymers, 72, 521-526. https://doi.org/10.1016/j.carbpol.2007.09.019

[62] Lopez, O.V., Castillo, L.A., Garcia, M.A., Villar, M.A. and Barbosa, S.E. (2015) Food Packaging Bags Based on Thermoplastic Corn Starch Reinforced with Talc Nanoparticles. Food Hydrocolloids, 43, 18-24. https://doi.org/10.1016/j.foodhyd.2014.04.021

[63] Jumaidin, R., Sapuan, S.M., Jawaid, M., Ishak, M.R. and Sahari, J. (2017) Effect of Agar on Flexural, Impact, and Thermogravimetric Properties of Thermoplastic Sugar Palm Starch. Current Organic Synthesis, 14, 200-205. https://doi.org/10.2174/1570179413666160921110732

[64] Noorbakhsh-Soltani, S.M., Zerafat, M.M. and Sabbaghi, S. (2018) A Comparative Study of Gelatin and Starch-Based Nano-Composite Films Modified by Nano-Cellulose and Chitosan for Food Packaging Application. Carbohydrate Poly- 
mers, 189, 48-55.

[65] Sanyang, M.L., Sapuan, S.M., Jawaid, M., Ishak, M.R. and Sahari, J. (2016) Development and Characterization of Sugar Palm Starch and Poly (Lactic Acid) Bilayer Films. Carbohydrate Polymers, 146, 36-45.

https://doi.org/10.1016/j.carbpol.2016.03.051

[66] Masmoudi, F., Bessadok, A., Dammak, M., Jaziri, M. and Ammar, E. (2016) Biodegradable Packaging Materials Conception Based on Starch and Polylactic Acid (PLA) Reinforced with Cellulose. Environmental Science and Pollution Research, 23, 20904-20914. https://doi.org/10.1007/s11356-016-7276-y

[67] Sorrentino, A., Gorrasi, G. and Vittoria, V. (2007) Potential Perspectives of Bio-Nanocomposites for Food Packaging Applications. Trends in Food Science and Technology, 18, 84-95. https://doi.org/10.1016/j.tifs.2006.09.004

[68] Otey, F.H. and Westhoff, R.P. (1982) Biodegradable Starch-Based Blown Films. US 4337181 A, 29 June 1982.

[69] Erica, B. (2015) Bioplastics. US 9085677 B2, 21 July 2015.

[70] Villada Castillo, H.S., Navia Porras, D.P. and Castaneda Nino, J.P. (2016) Biodegradable Films Obtained from Cassava Starch and Their Manufacture Process. WO 2013042083 A1, 16 Aug. 2016.

[71] Ghanbarzadeh, B., Almasi, H. and Entezami, A.A. (2011) Improving the Barrier and Mechanical Properties of Corn Starch-Based Edible Films: Effect of Citric Acid and Carboxymethyl Cellulose. Industrial Crops and Products, 33, 229-235. https://doi.org/10.1016/j.indcrop.2010.10.016

[72] López, O.V., Lecot, C.J., Zaritzky, N.E. and García, M.A. (2011) Biodegradable Packages Development from Starch Based Heat Sealable Films. Journal of Food Engineering, 105, 254-263. https://doi.org/10.1016/j.jfoodeng.2011.02.029

[73] Dias, A.B., Müller, C.M.O., Larotonda, F.D.S. and Laurindo, J.B. (2010) Biodegradable Films Based on Rice Starch and Rice Flour. Journal of Cereal Science, 51, 213-219. https://doi.org/10.1016/j.jcs.2009.11.014

[74] Balakrishnan, S., Gopi, S. and Thomas, U.V. (2017) Resistant Transparent Bionanocomposite Films Based on Potato Starch/Cellulose for Sustainable Packaging. Starch/Stärke.

[75] Medina-Jaramillo, C., Ochoa-Yepes, O., Bernal, C. and Famá, L. (2017) Active and Smart Biodegradable Packaging Based on Starch and Natural Extracts. Carbohydrate Polymers, 176, 187-194. https://doi.org/10.1016/j.carbpol.2017.08.079

[76] Nikolic, V., Velickovic, S. and Popovic, A. (2014) Biodegradation of Polystyrene-Graft-Starch Copolymers in Three Different Types of Soil. Environmental Science and Pollution Research, 21, 9877-9886.

https://doi.org/10.1007/s11356-014-2946-0 